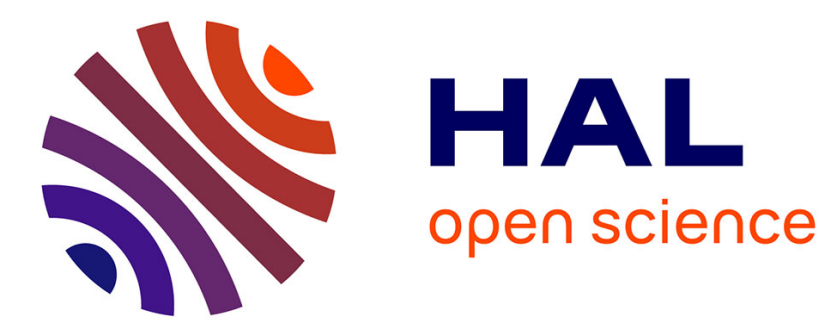

\title{
Convergence in Per Capita Health Expenditures and Health Outcomes in the OECD Countries
}

Ekaterini Panopoulou, Theologos Pantelidis

\section{To cite this version:}

Ekaterini Panopoulou, Theologos Pantelidis. Convergence in Per Capita Health Expenditures and Health Outcomes in the OECD Countries. Applied Economics, 2011, pp.1. 10.1080/00036846.2011.583222. hal-00712384

\section{HAL Id: hal-00712384 \\ https://hal.science/hal-00712384}

Submitted on 27 Jun 2012

HAL is a multi-disciplinary open access archive for the deposit and dissemination of scientific research documents, whether they are published or not. The documents may come from teaching and research institutions in France or abroad, or from public or private research centers.
L'archive ouverte pluridisciplinaire HAL, est destinée au dépôt et à la diffusion de documents scientifiques de niveau recherche, publiés ou non, émanant des établissements d'enseignement et de recherche français ou étrangers, des laboratoires publics ou privés. 


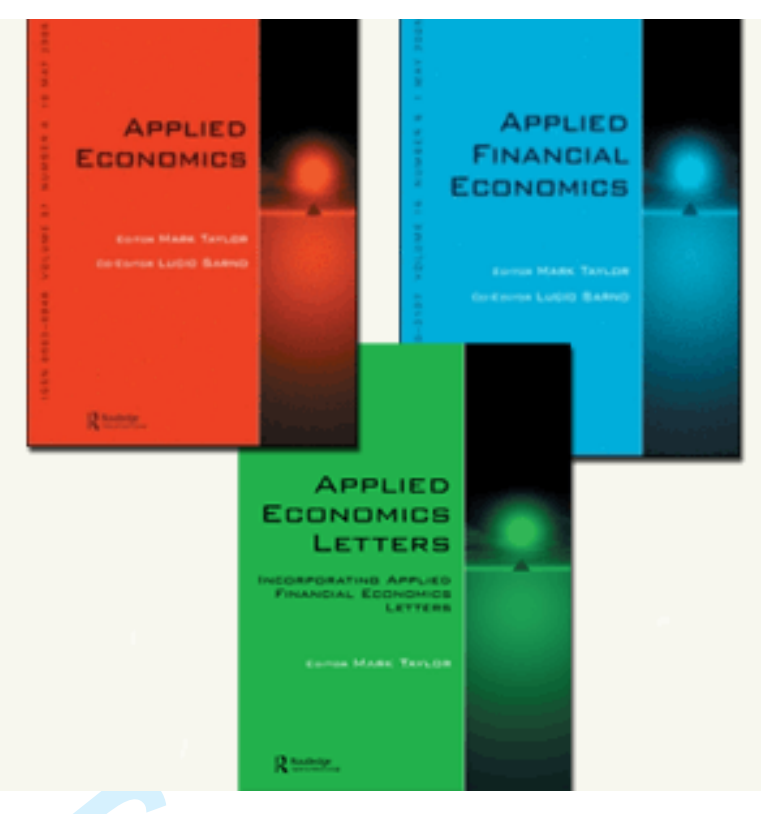

\section{Convergence in Per Capita Health Expenditures and Health Outcomes in the OECD Countries}

\begin{tabular}{|r|l|}
\hline Journal: & Applied Economics \\
\hline Manuscript ID: & APE-2009-0571.R1 \\
\hline Journal Selection: & Applied Economics \\
\hline Date Submitted by the \\
Author: & 11-Oct-2010 \\
\hline Complete List of Authors: & $\begin{array}{l}\text { Panopoulou, Ekaterini; University of Piraeus, Department of } \\
\text { Statistics and Insurance Science } \\
\text { Pantelidis, Theologos; University of Crete, Department of } \\
\text { Economics }\end{array}$ \\
\hline JEL Code: & $\begin{array}{l}\text { C23 - Models with Panel Data < C2 - Econometric Methods: Single } \\
\text { Equation Models < C - Mathematical and Quantitative Methods, I10 } \\
\text { - General < I1 - Health < I - Health, Education, and Welfare }\end{array}$ \\
\hline Keywords: & $\begin{array}{l}\text { Convergence clubs, health expenditure, health determinants, health } \\
\text { outcomes, OECD countries }\end{array}$ \\
\hline
\end{tabular}

\section{SCHOLARONE ${ }^{\text {m }}$ \\ Manuscripts}




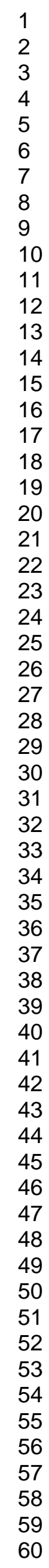

14

15

16

18

19

20

22

23

25

26

27

29

30

32

33

34

35

36

37

39

40

41

42

44

45

46

47

48

49

51

52

54

55

57

58

59

60

Editorial Office, Dept of Economics, Warwick University, Coventry CV4 7AL, UK 


\title{
Convergence in Per Capita Health Expenditures and Health Outcomes in the OECD Countries
}

\author{
Ekaterini Panopoulou* \\ Department of Statistics and Insurance Science, University of Piraeus. \\ Theologos Pantelidis ${ }^{\dagger}$ \\ Department of Economics, University of Crete
}

\begin{abstract}
Our analysis of 19 OECD countries over the period 1972-2006 provides evidence of convergence in per capita health care expenditures for 17 countries, while the US and (to a lesser degree) Norway follow a different path. A simple decomposition of per capita health expenditures reveals that the divergence of the US comes from the divergence of the 'ratio of health care expenditures to GDP' component, while Norway's divergence is mainly caused by the 'labour productivity' component. Interestingly, our results suggest that convergence in per capita health expenditures among the 17 OECD countries does not lead to convergence in health outcomes. Finally, we extend our analysis to examine convergence in various determinants of health expenditures.
\end{abstract}

JEL Classification: C23; I10.

Keywords: Convergence clubs; health expenditure; health determinants; health outcomes; OECD countries.

Running Title: Convergence in per capita Health Expenditures and Health Outcomes

\footnotetext{
${ }^{*}$ Ekaterini Panopoulou, Department of Statistics and Insurance Science, University of Piraeus, 80 Karaoli \& Dimitriou Str., 18534, Piraeus, Greece. E-mail: apano@unipi.gr. Tel: 00302104142728. Fax: 00302104142340.

${ }^{\dagger}$ Correspondence to: Theologos Pantelidis, Department of Economics, University of Crete, Panepistimioupoli Gallou, 74100 Rethymno, Greece. E-mail: pantelidis@econ.soc.uoc.gr. Tel: 0030 2831077410. Fax: 00302831077404.
} 


\section{Introduction}

Health care expenditure has been rising rapidly in the developed countries in the recent years. This rise constitutes a major concern for health policy makers. In this respect, research has focused on the determinants of health care expenditure with income growth being the undebatable determinant (see, inter alia, Hitiris and Posnett, 1992; Hansen and King, 1996; Di Matteo and Di Matteo, 1998; Karatzas, 2000; Herwartz and Theilen, 2003; Wang, 2009a; Cantarero and Lago-Penas, 2010). The long run elasticity of health expenditure on growth and the question of whether health is a luxury good has attracted attention by another line of the literature that focuses on the integration and cointegration properties of the variables of interest (see, inter alia, Hansen and King, 1996; Hitiris, 1997; McCoskey and Selden, 1998; Gerdtham and Lothgren, 2000; MacDonald and Hopkins, 2002; Jewell et al., 2003; Clemente et al., 2004; Ang, 2010).

Despite its potential importance and usefulness, the analysis of cross-country disparities in this context has not received much attention as very few studies focus on the issue of health care convergence for a set of countries. Hitiris (1997) examines whether health expenditures converge for a group of European Community countries and finds no evidence of convergence. He argues that economic convergence of the EU members will eventually lead to convergence of health expenditure. In a more recent study, Hitiris and Nixon (2001) find that EU economic integration leads to income convergence and to convergence in various sectors and the health sector in particular. However, the authors conclude that there is no clear evidence in favour of the existence of a single health function for all the EU member states. Such a case can become even more complex if the analysis is extended to cover the OECD countries. Employing an empirical growth theoretical framework in order to examine the determinants of growth of per capita health expenditures for 24 OECD countries, Barros (1998) finds that the higher the health care expenditures per capita are, the lower the growth rate is. The author suggests that this is an indication of convergence of health care expenditures. The rapid growth in US health care expenditure and the 'catch-up' hypothesis in the 
OECD countries is the focus of Narayan's (2007) study. Specifically the author examines whether per capita health expenditures of Canada, Japan, Spain, Switzerland and the UK converge to the US per capita health expenditures and finds strong evidence in favour of convergence. ${ }^{1}$

Taking a different route, Alcande-Unzu et al. (2009) address the issue of cross country disparities in health care expenditure by employing a factor decomposition model. The authors extend the decomposition of Cheng and Li (2006) to include per capita health care expenditure and show that it can be expressed as the product of the ratio of health care expenditures to GDP, labour productivity, employment rate, activity rate and the ratio of working age population to total population. Their findings suggest that the main determinants of cross-country dispersion in per capita health care expenditure are the ratio of health care expenditures to GDP and labour productivity.

This factor decomposition is the starting point of our analysis. Specifically, the first objective of our analysis is to examine convergence in per capita health expenditures for a group of 19 OECD countries over the period 1972-2006 and use the aforementioned decomposition to identify the reasons for the observed divergent behaviour of some countries. It is obvious that the examination of the economic characteristics that lead to health expenditure convergence/divergence is critical for policymakers since the majority of the OECD countries face budget deficits. Health care spending has put a pressure on public budgets during the past two decades. Moreover, evidence on convergence would point to increased expenditure on health and thus increased deficits, unless some other sectors, such as education and other public services have to be sacrificed. This can potentially be a contentious issue in some countries. Our results suggest convergence in per capita health expenditures among 17 OECD countries, while Norway and especially the US follow a different path with substantially higher per capita health expenditures. It turns out that the divergence of the US comes from

\footnotetext{
${ }^{1}$ Wang (2009b) also focuses on the degree of convergence of US health care expenditures and its major components using state level data. His findings point to moderate convergence in total health care costs accompanied by divergence in the components.
} 
the divergence in the 'ratio of health care expenditures to GDP' component, while Norway's divergence is mainly caused by the 'labour productivity' component.

We also move one step forward and investigate whether convergence in per capita health expenditures implies convergence in health outcomes as well. Interestingly, our results show that convergence in per capita health expenditures does not, in general, lead to convergence in health outcomes. Finally, we extend our analysis to provide some insights into the cross-country disparities in major determinants of health expenditures.

We should note that our analysis is based on a new methodology introduced by Phillips and Sul (2007a, PS henceforth). This methodology has two important advantages compared to alternative approaches available in the literature. First, it is based on a nonlinear time-varying factor model that incorporates the possibility of transitional heterogeneity or even transitional divergence. Moreover, the methodology is robust to the stationarity properties of the series under scrutiny. Second, and more importantly, this methodology provides a simple empirical algorithm that can be used to identify groups of countries that converge to different equilibria when the full panel of the countries under scrutiny diverge. Moreover the algorithm also detects individual countries that diverge from the panel. This enables us to identify the reasons for the divergent behaviour of some countries.

The rest of the paper is organised as follows. Section 2 describes the methodology we use to examine health convergence among the OECD countries. Sections 3-5 report our empirical findings and Section 6 concludes the paper.

\section{Econometric Methodology}

In this section, we outline the econometric methodology we employ to examine the existence of convergence in per capita health care expenditure, health outcomes and various determinants of health expenditures. The methodology was introduced by PS in order to test for conditional sigma convergence in a panel of countries. We also briefly discuss the clustering algorithm, put forward by PS and employed in Phillips 
and Sul (2007b, 2009), which allows us to classify countries into convergence subgroups in cases where the full panel diverges.

\subsection{The $\log t$ Test}

Suppose that we have panel data for a variable $X_{i t}, i=1, \ldots N$ and $t=1, \ldots T$ where $N$ and $T$ are the number of countries and the sample size respectively.

PS decompose $X_{i t}$ into the systematic, $g_{i t}$, and the transitory, $a_{i t}$, components. In other words,

$$
X_{i t}=g_{i t}+a_{i t}
$$

We can discriminate between the common and idiosyncratic components of the panel by using the following transformation of (1):

$$
X_{i t}=\left(\frac{g_{i t}+a_{i t}}{\mu_{t}}\right) \mu_{t}=\delta_{i t} \mu_{t}, \text { for all } i, t
$$

In this way, the variable of interest, $X_{i t}$, is decomposed in two components, one common, $\mu_{t}$, and one idiosyncratic, $\delta_{i t}$, both of which are time-varying. The idiosyncratic component, $\delta_{i t}$, is a measure of the distance between $X_{i t}$ and the common component, $\mu_{t}$. This formulation allows us to test for convergence by testing whether the factor loadings $\delta_{i t}$ converge to a constant, $\delta$, by taking ratios instead of differences and thus eliminating the common component. To do so, PS define the relative transition parameter, $h_{i t}$, as

$$
h_{i t}=\frac{X_{i t}}{\frac{1}{N} \sum_{i=1}^{N} X_{i t}}=\frac{\delta_{i t}}{\frac{1}{N} \sum_{i=1}^{N} \delta_{i t}}
$$

which measures the loading coefficient $\delta_{i t}$ in relation to the panel average and as such the transition path for the variable of interest of country $i$ relative to the panel average. Whenever the factor loadings $\delta_{i t}$ converge to a constant, $\delta, h_{i t}$ converges to unity and the cross-sectional variation $\left(H_{t}\right)$ of the relative transition path converges to zero as 
$t \rightarrow \infty$, i.e.

$$
H_{t}=\frac{1}{N} \sum_{i=1}^{N}\left(h_{i t}-1\right)^{2} \rightarrow 0, \text { as } t \rightarrow \infty
$$

Note that the cross-sectional mean of the relative transition paths, $h_{i t}$, is unity by construction. PS implement the following semiparametric model for $\delta_{i t}$ :

$$
\delta_{i t}=\delta_{i}+\frac{\sigma_{i} \xi_{i t}}{L(t) t^{\alpha}}
$$

where $\xi_{i t} \sim \operatorname{iid}(0,1)$ across $i, \sigma_{i}$ are idiosyncratic scale parameters, $L(t)$ is a slowly varying function, such as $\log (t)$ for which $L(t) \rightarrow \infty$ as $t \rightarrow \infty$, and $\alpha$ denotes the speed of convergence, i.e. the rate at which this cross-sectional variation decays to zero. This representation ensures that $\delta_{i t}$ converges to $\delta_{i}$ whenever $\alpha \succeq 0$. The null hypothesis of convergence is as follows:

$$
\mathcal{H}_{0}: \delta_{i}=\delta \text { and } \alpha \succeq 0
$$

while the alternative is

$$
\mathcal{H}_{A}: \delta_{i} \neq \delta \text { for all } i \text { or } \alpha \prec 0
$$

The null hypothesis implies convergence for all countries, while the alternative hypothesis implies no convergence for some countries. The alternative hypothesis can accommodate both overall divergence and club convergence, i.e. the possibility that some of the countries under scrutiny form convergent groups at different factor loadings, say $\delta_{1}$ and $\delta_{2}$. The following subsection describes an empirical algorithm that can be implemented to identify such convergent subgroups. PS show that under convergence, $H_{t}$ has the following limiting form

$$
H_{t} \backsim \frac{A}{L(t)^{2} t^{2 \alpha}}, \text { as } t \rightarrow \infty
$$

where $A$ is a strictly positive constant.

Now, consider the ratio $H_{1} / H_{t}$ that measures the distance of the panel from the 
common limit. We can easily test $\mathcal{H}_{0}$ based on the following logt regression

$$
\log \left(H_{1} / H_{t}\right)-2 \log L(t)=\widehat{c}+\widehat{b} \log t+u_{t}, t=[r T], \ldots, T
$$

where $L(t)=\log (t)$ and $r>0$. Specifically, the regression is run after a fraction $(r)$ of the sample is removed. PS recommend setting $r$ equal to 0.3 , since extensive Monte Carlo simulations show that this choice of $r$ is satisfactory in terms of both size and power properties of the test.

The fitted coefficient $\widehat{b}$ of logt converges to the speed of convergence parameter $2 \alpha$ under the null hypothesis of convergence where $\widehat{\alpha}$ is the estimate of $\alpha$ in $\mathcal{H}_{0}$ (see also equation (4)). We focus on the sign of the estimated coefficient, $\widehat{b}$, since convergence of the full panel requires that $b$ is either positive or equal to zero. This is tested by means of the conventional t-statistic, $t_{b}$, that is, convergence is supported if $t_{b} \succ-1.65$. The standard error of our estimates is calculated using a HAC estimator for the long-run variance of the residuals. In this study, we employ the Quadratic spectral kernel and determine the bandwidth by means of the Andrews (1991) data-dependent procedure. Finally, we should note that the size of $b$ indicates the speed of convergence (for positive values). That is, high values of $b$ suggest a fast rate of convergence.

The aforementioned convergence test has numerous advantages over existing ones. First, the methodology does not rely on any particular assumption concerning trend stationarity or stochastic nonstationarity. Second, it is based on a model that incorporates the possibility of transitional heterogeneity or even transitional divergence. This is crucial since it is not proper to test for convergence by means of standard unit root and cointegration tests in the presence of heterogeneity. For example, PS show that two series can converge even if they are not cointegrated (this is the case of asymptotic cointegration). Thus, the methodology of PS can be considered as an asymptotic cointegration test that does not suffer from the small sample problems of standard unit root and cointegration tests. Third, when the full panel of the countries under scrutiny diverges, the methodology provides a simple empirical algorithm (described in 
the following section) that can be used to identify groups of countries that converge to different equilibria and at the same time allow individual countries to diverge.

\subsection{Club Convergence Algorithm}

Whenever a researcher examines convergence within a panel of countries, it is often the case that the full panel diverges. In such cases, PS propose an empirical algorithm that can be used to determine subgroups of countries that converge to different steady states. We now briefly describe the four steps of this empirical algorithm.

- Step 1 (Ordering): We order the members of the panel according to the last observation, since evidence of convergence will, in general, be most apparent in the recent years. Alternatively, the ordering of the series can be done based on a time series average of the final observations.

- Step 2 (Core Group Formation): We try to identify a core group of countries that provide strong evidence of convergence. Specifically, we estimate a sequence of logt regressions using the $k$ highest members (Step 1) for all different values of $k$ (i.e. $2 \leq k<N$ ). We choose the regression that generates the maximum convergence t-statistic $t_{b, k}$ (where $t_{b, k}>-1.65$ so that convergence is ensured for the corresponding group). The corresponding group forms the core convergence group.

- Step 3 (Club Membership): We now evaluate each individual country not included in the core convergence group (Step 2) for membership in this group. More in detail, we add one country at a time and calculate the convergence t-statistic from the logt regression. The new country (member) satisfies the membership condition if the associated t-statistic is greater than a chosen critical value $c^{*}$ (i.e. $t_{b}>c^{*}$ ). All countries that satisfy the membership condition are added to the core convergence group. Finally, we check whether the whole group (i.e. the members of the initial core group and the additional selected members) satisfies 
the criterion for convergence.

- Step 4 (Recursion and Stopping): We run the logt regression for all the countries not included in the club formed in the previous step. If the corresponding $t$ statistic indicates convergence, these countries form a second convergence club. Otherwise, Steps 1 to 3 are repeated in order to reveal additional subconvergence clusters. If no core group can be found (Step 2), then these countries display a divergent behaviour.

\section{Factor decomposition of per capita health care expen- diture}

In this section we describe the methodology employed to decompose per capita health care expenditures in factors and then apply the econometric methodology described in the previous section to reveal cross-country disparities among the OECD countries.

The decomposition methodology we employ comes from the literature of per capita income convergence and was proposed by Cheng and Li (2006). The authors show that per capita GDP can be decomposed into the product of labour productivity, employment rate, activity rate and the ratio of working age population to total population. Alcalde-Unzu et al. (2009) extend this decomposition to include per capita health care expenditure and show that it can be expressed as the product of the ratio of health care expenditures to GDP, labour productivity, employment rate, activity rate and the ratio of working age population to total population.

More in detail, let $x_{i t}$ denote the per capita health care expenditure in country $i$ in period $t$. It can be calculated by dividing health care expenditure $\left(H_{i t}\right)$ and the total population in country $i\left(N_{i t}\right)$. In the same manner, we let $Y_{i t}, E_{i t}, A_{i t}$ and $W_{i t}$ be country's $i$ GDP, total employment, active population and working-age population, respectively. It is easy to see that per capita health care expenditure can be written as the product of the following factors: the ratio of health care expenditures to GDP 
$\left(s_{i t}=H_{i t} / Y_{i t}\right)$, labour productivity $\left(y_{i t}=Y_{i t} / E_{i t}\right)$, employment rate $\left(e_{i t}=E_{i t} / A_{i t}\right)$, activity rate $\left(a_{i t}=A_{i t} / W_{i t}\right)$ and the proportion of working age population in total population $\left(w_{i t}=W_{i t} / N_{i t}\right)$. As a result, the variable of interest, $x_{i t}$, can be written as follows:

$$
x_{i t} \equiv s_{i t} \cdot y_{i t} \cdot e_{i t} \cdot a_{i t} \cdot w_{i t}
$$

We are interested in examining convergence in per capita health care expenditures. The data we employ are taken from the OECD Health Database (OECD, 2008). Since our methodology requires a balanced panel, we end up with 19 OECD countries examined over the period 1972-2006. The countries under scrutiny are listed in Table 1, Panel A. The same table (Panel B) contains a list of variables' definitions and conversions employed. ${ }^{2}$

We first employ the $\log t$ test for the panel of per capita health care expenditures, $x_{i t}$, for the 19 countries under scrutiny. The point estimate of $b$, reported in Table 2 , is statistically less than zero $\left(\widehat{b}=-0.471, t_{b}=-5.024\right)$ suggesting divergence of the 19 OECD countries. Afterwards, we implement the algorithm described in Section 2.2 to identify subgroups of countries that converge to different equilibria. Our results indicate that the countries under examination are divided into two convergence clubs. Specifically, the first convergence club contains Norway and the US with substantially higher per capita health expenditures compared to the remaining 17 countries that form the second club.

Figure 1 presents the relative transition paths, $h_{i t}$, calculated based on equation (3) for Norway, the US and the remaining countries (calculated as the cross-country average of their relative transition paths). Each transition path shows the position of the country or club relative to the panel average. The 19-country average corresponds to the unity level. A transition path below unity indicates that the level of the country or club is below the panel average, while a transition path above unity indicates that

\footnotetext{
${ }^{2}$ Note that the period and countries under scrutiny are slightly different for some of the variables examined in the following sections. The relevant information is reported in Panel B of Table 1.
} 
the level of the country or club is above the panel average. It is clear that Norway and especially the US appear to be away and above the other countries, while their divergence from the panel increases over time. Interestingly, Norway's per capita health care expenditures are initially below the panel average with a constant increasing trend though. As a result, Norway is well above the average during the recent years.

It is now of great interest to identify the reasons of divergence for Norway and the US from the rest of OECD countries. We can investigate this issue based on the decomposition of per capita health expenditures given in equation (5). Specifically, we examine convergence among the 19 OECD countries included in our analysis for each one of the five factors reported in equation (5). The results are reported in Table 2 and can be summarised as follows.

1. There is full convergence among the 19 countries for three out of five factors, namely the employment rate $\left(e_{i t}\right)$, the activity rate $\left(a_{i t}\right)$ and the proportion of working age population in total population $\left(w_{i t}\right)$. Convergence is faster for $e_{i t}$ and $w_{i t}$ (the estimated values of $b$ are statistically greater than zero) and slower for the activity rate (the estimated $b$ is not statistically different from zero). As a conclusion, none of these three factors can account for the divergent behaviour of Norway and the US in per capita health expenditures.

2. There is no full convergence in the ratio of health care expenditures to GDP $\left(s_{i t}\right)$ as suggested by the negative and statistically significant estimated value of $b$ $\widehat{(b}=-0.85)$. The implementation of the club convergence algorithm reveals that Ireland and the US diverge from the remaining 17 countries following a different path each. To be more specific, Ireland moves below but close to the 17 countries, while the US is well above the panel average. Interestingly, the divergence of the US from the other OECD countries increases over time. This is illustrated at the left-hand side plot of Figure 2 that presents the position of Ireland and the US relative to the other OECD countries (for $s_{i t}$ ). It is therefore clear that the divergence of the US per capita health care expenditures from the other countries 
under scrutiny comes from its divergence in $s_{i t}$.

3. Similarly, there is no full convergence in labour productivity $(\widehat{b}=-0.562)$. The countries form two convergence clubs. The first club includes Iceland, Japan, New Zealand, Portugal, Spain and Switzerland, while the remaining countries form the second club. The relative position of the two clubs is revealed in the right-hand side plot of Figure 2 that also shows the position of Norway in a separate line. We observe that over the recent years Norway displays an upward tendency moving away from the panel average. We therefore suspect that the divergence of Norway from the other countries in per capita health care expenditures is mainly caused by the labour productivity component.

\section{Convergence in Health Outcomes}

The analysis so far has shown that OECD countries broadly converge as far as per capita health expenditure is considered (with the exception of the US and, to a lesser degree, Norway). Does this convergence imply convergence in health outcomes as well? The link between additional health expenditure and patient benefits, i.e. improved health outcomes is one of the fundamental and yet unresolved issues in health policy.

Employing a cross-section of 18 developed countries, Cochrane et al. (1978) examine the relationship between mortality rates, GNP and consumption of inputs such as health care provision. They find that health care inputs are not in general associated with health outcomes, such as mortality rates. To avoid international heterogeneity, Cremieux et al. (1999) examine the relationship between expenditure and outcomes across 10 Canadian provinces over the 15-year period 1978-1992. Their results point to a significant link between lower health-care spending and a significant increase in infant mortality along with a decrease in life expectancy. Or's (2001) study of the determinants of variations in mortality rates across 21 OECD countries between 1970 and 1995 reveals that health expenditure is significant on health for women proxied by 
potential years of life lost, but not for men. In a detailed review, Nixon and Ulmann (2006) refer to 16 studies that have examined the issue providing a variety of results. In their own study, they employ data for 15 EU countries over the period 1980-1995 and three health outcomes measures - life expectancy at birth for males and females, and the infant mortality rate - and conclude that although health expenditure and the number of physicians have made a significant contribution to improvements in infant mortality, '... health care expenditure has made a relatively marginal contribution to the improvements in life expectancy in the EU countries over the period of the analysis'. More recently, Martin et al. (2008) take advantage of a major new dataset developed in English health care, in the form of programme budgets, which enables them to address some of the difficulties associated with estimating the impact of health care expenditure on health outcomes in two of the largest programmes of health care: circulatory disease and cancer. Their study shows that health care expenditure has a strong positive effect on outcomes in the two programmes of care investigated.

Following the extant literature, we proxy health outcomes with the following variables: life expectancy (females), life expectancy (males), life expectancy (total population), crude mortality rate, infant mortality and potential years of life lost. ${ }^{3}$ For each one of the aforementioned health outcomes we implement the $\log t$ test to examine convergence among the countries under scrutiny. When testing for convergence of the full panel of 19 countries, the results, reported in Panel A of Table 3, suggest that convergence occurs only for infant mortality. For all the other variables the null hypothesis of convergence is rejected. In general, the main conclusion drawn from Panel A of Table 3 is that the existence of convergence among 17 of the 19 countries under examination in per capita health expenditures does not lead to convergence in health outcomes.

Moreover, the implementation of the club convergence algorithm leads to the formulation of various convergence clubs that differ for each one of the variables considered

\footnotetext{
${ }^{3}$ The variable definitions are given in Table 1 (Panel B).
} 
in this study. Our findings of the club convergence algorithm, reported in Figure 3, may be summarised as follows:

1. There is a core group of six countries that converge for all the variables considered in this section. This group contains Austria, Canada, Germany, Norway, Spain and the UK. Furthermore, Finland and Ireland deviate from this core group only in the case of life expectancy of males. Similarly, New Zealand does not belong to this core group only for the total life expectancy variable.

2. In most cases, Japan behaves in a totally different way compared to the other OECD countries. A typical example is the mortality rate where 17 of the 19 countries form two convergence clubs while Japan (and Sweden) diverges following its own different path. On the whole, Japan's health outcomes are better off compared to the panel average. Specifically, Japan belongs to above average groups for all life expectancy measures, below average for the mortality rate and the middle group for the potential years of life lost variable.

3. Contrary to Japan and despite the high per capita health expenditure level, US health outcomes are worse off compared to the other OECD countries. More in detail, the US are below the panel average with respect to all life expectancy measures and above the panel average when mortality rate and potential years of life lost are considered.

\section{Convergence in Health Determinants}

'What determines the quantity of resources a country devotes to medical care?' Professor Newhouse (1977) asked some 30 years ago. Employing a cross-section regression of per capita health expenditure on per capita GDP in 13 OECD countries, he inferred that per capita GDP accounted for $92 \%$ of the sample variation in health expenditure. Moreover, the estimated elasticity (greater than one) implied that health care is a "luxury" good, rather than a necessity. Since this seminal paper, attention has been paid on 
the integration and cointegration properties of health expenditure and GDP (see, inter alia, Hansen and King, 1996; Hitiris, 1997; McCoskey and Selden, 1998; Gerdtham and Lothgren, 2000; MacDonald and Hopkins, 2002; Jewell et al., 2003; Clemente et al., 2004). Another strand of the literature focuses on revealing the determinants of health expenditures (see, inter alia, Hitiris and Posnett, 1992; Hansen and King, 1996; Di Matteo and Di Matteo, 1998; Karatzas, 2000; Herwartz and Theilen, 2003). The key variables employed in the literature as determinants of health expenditure can be broadly categorised as economic, health stock, institutional, demographic and life-style variables.

In this section, we attempt to reveal cross-country disparities among the OECD countries with respect to the basic determinants of health expenditure. Our choice of variables is limited by data availability. For example, health stock variables are not included in our analysis as we could not get a sufficient number of cross-section and time-series observations.

With respect to the economic variables, the variables we employ are (i) per capita GDP, (ii) income equality measured by the share of nominal wages in nominal GDP, (iii) the inflation rate measured by the growth rate of the GDP deflator as wages in the health sector will rise proportionally and (iv) the 'Baumol variable' measured by the difference between wage increases and labour productivity. ${ }^{4}$ Health care expenditure also depends on the nature of the health system. We expect public reimbursement systems to raise health spending. A proxy for the nature of the health system of each country is the proportion of public health expenditure in total health expenditure. The results of the $\log t$ test, presented in Table 3 (Panel B), suggest convergence among the OECD countries for all economic determinants except for income equality. In the latter case, the countries form three convergence clubs, while Ireland diverges. ${ }^{5}$

Furthermore, the demographic structure of the population affects health expen-

\footnotetext{
${ }^{4}$ Baumol (1988) argues that the health sector is a service sector and as such, productivity gains may be lower than the rest of the economy. For a detailed analysis, see Hartwig (2008).

${ }^{5}$ To reserve space we do not report club convergence results for health determinants. These are available from the authors upon request.
} 
diture as certain categories of the population tend to consume more health related products. Among the demographic variables employed in the literature are the following: (i) the dependency ratio measured by the ratio of the population under 14 and over 65 over the population aged 15-64, (ii) the ratio of the population aged under 14 to total population, (iii) the ratio of the population aged over 65 to total population, and (iv) the female labour force participation rate. Table 3 (Panel C) reports the results for the convergence tests for the aforementioned demographic variables. The results suggest full convergence for the dependency ratio and the female labour force participation rate. In both cases, convergence is fast since the estimated value of $b$ is positive ( $b$ equals 0.915 and 1.156 for the dependency ratio and the female labour force participation rate respectively) and statistically different from zero. On the other hand, there is divergence among the OECD countries for the other two demographic variables considered in this study. In both cases, the countries form two clubs that converge to different steady states.

Lastly, countries differ with respect to lifestyle and consumption behaviour and in this respect they are exposed to different types of diseases. This means that the probability for all types of illnesses will differ from country to country leading countries to target specific types of diseases. Altering the lifestyle and consumption behaviour of people is feasible through spending more on preventive health care. For the purpose of our analysis we employ the following variables: (i) sugar consumption, (ii) fruits \& vegetables consumption, (iii) tobacco consumption and (iv) alcohol consumption. The results, reported in Table 3 (Panel D), indicate convergence in alcohol consumption among the OECD countries under scrutiny (at a slow rate as suggested by the estimate of $b$ that is not statistically different from zero). On the other hand, the OECD countries diverge for the other three variables considered in our analysis. Specifically, in the case of tobacco consumption the countries form three convergence clubs. Finally, the results for the nutrition-related variables (i.e. sugar consumption and fruits \& vegetables consumption) suggest that the OECD countries are, in general, divided into two groups 
with different nutrition habits.

\section{Conclusions}

The issue of health care expenditure has attracted the interest of many researchers over the last 30 years. This study contributes to the existing literature by examining convergence in per capita health care expenditure among 19 countries for the period 1972-2006 by means of a new methodology introduced by Phillips and Sul (2007a). From an empirical point of view, the main advantage of this methodology (in addition to its robustness to the stationarity properties of the series under scrutiny) is the provision of a simple algorithm that can be used to identify groups of countries that converge to different equilibria when the full panel of countries under examination diverges.

Our results support the existence of convergence in per capita health care expenditures for 17 countries, while the US and, to a lesser degree, Norway follow a different path with substantially higher per capita health expenditures. We then decompose per capita health expenditures into five components and examine convergence among the OECD countries for each one of the components. In this way, we are able to identify what causes the divergent behaviour of Norway and the US. It turns out that divergence of the US comes from the divergence in the 'ratio of health care expenditures to GDP' component, while Norway's divergence is probably caused by the 'labour productivity' component.

Moreover, we investigate whether convergence in per capita health expenditures among the majority of the OECD countries under scrutiny is accompanied by convergence in health outcomes. Specifically, we use six different health outcomes. With the exception of infant mortality, there is divergence of the full panel of OECD countries for all the health outcomes considered in this study, although we can still identify groups of countries that converge to different steady states. We, therefore, conclude that convergence in per capita health expenditures does not lead to convergence in 
health outcomes. Finally, we examine convergence in various determinants of health expenditures. Our findings support (i) convergence in all economic determinants examined in this study with the exception of income equality and (ii) club convergence in most of the demographic and life-style variables under investigation.

Acknowledgements: We would like to thank Donggyu Sul for making the Gauss code available to us. We are also grateful to an anonymous referee for useful comments and suggestions. Finally, the authors would like to thank the University of Crete for financial support under the KA 2877 research grant of the "Program of Financing Basic Research". 


\section{References}

[1] Alcalde-Unzu, J., Ezcurra R., Pascual, P., 2009. Cross-country disparities in health care expenditure: a factor decomposition. Health Economics 18, 479-485.

[2] Andrews, DWK., 1991. Heteroskedasticity and autocorrelation consistent covariance matrix estimation. Econometrica 59, 817-858.

[3] Ang, JB., 2010. The determinants of health care expenditure in Australia. Applied Economics Letters 17, 639-644.

[4] Barros PP., 1998. The black box of health care expenditure growth determinants. Health Economics 7, 538-544.

[5] Baumol, W., 1988. Containing the medical cost: why price controls wouldn't work. The Public Interest 93, 37-54.

[6] Cantarero, D., Lago-Penas, S., 2010. The determinants of health care expenditure: a reexamination. Applied Economics Letters 17, 723-726.

[7] Cheng, Y., Li, S., 2006. Income inequality and efficiency: a decomposition approach and applications to China. Economics Letters 91, 8-14.

[8] Clemente, J., Marcuello, C., Montanes, A., Pueyo, F., 2004. On the international stability of health care expenditure functions: are government and private functions similar? Journal of Health Economics 23, 589-613.

[9] Cochrane, A., St Leger, A., Moore, S.F., 1978. Health service 'input' and mortality 'output' in developed countries. Journal of Epidemiology and Community Health $32,200-205$.

[10] Cremieux, P., Ouellette, P., Pilon, C., 1999. Health care spending as determinants of health outcomes. Health Economics 8, 627-639. 
[11] Di Matteo, L., Di Matteo, R., 1998. Evidence on the determinants of Canadian provincial government health expenditures:1965-1991. Journal of Health Economics $17,211-228$.

[12] Gerdtham, U.-G., Lothgren, M., 2000. On stationarity and cointegration of international health expenditures and GDP. Journal of Health Economics 19, 461-475.

[13] Hansen, P., King, A., 1996. The determinants of health care expenditure: a cointegration approach. Journal of Health Economics 15, 127-137.

[14] Hartwig, J., 2008. What drives health care expenditure?- Baumol's model of 'unbalanced growth' revisited. Journal of Health Economics 27, 603-623.

[15] Herwartz, H., Theilen, B., 2003. The determinants of health care expenditure: testing pooling restrictions in small samples. Health Economics 12, 113-124.

[16] Hitiris, T., 1997. Health care expenditure and integration in the countries of the European Union. Applied Economics 29,1-6.

[17] Hitiris, T., Nixon, J., 2001. Convergence of health care expenditure in the EU countries. Applied Economics Letters 8, 223-228.

[18] Hitiris, T., Posnett, J., 1992. The determinants and effects of health expenditure in developed countries. Journal of Health Economics 11, 173-181.

[19] Jewell, T., Lee, J., Tieslau, M., Strazicich, M.C., 2003. Stationarity of health expenditures and GDP: evidence from panel unit root tests with heterogeneous structural breaks. Journal of Health Economics 22, 313-323.

[20] Karatzas, G., 2000. On the determination of the US aggregate health care expenditure. Applied Economics, 32, 1085-1099.

[21] MacDonald, G., Hopkins, S., 2002. Unit root properties of OECD health care expenditure and GDP data. Health Economics 11, 371-376. 
[22] Martin, S., Rice, N., Smith, P., 2008. Does health care spending improve health outcomes? Evidence from English programme budgeting data. Journal of Health Economics 27, 826-842.

[23] McCoskey, S.K., Selden, T.M., 1998. Health care expenditures and GDP: panel data unit root results. Journal of Health Economics 17, 369-376.

[24] Narayan, P.K., 2007. Do health expenditures 'catch-up'? Evidence from OECD countries. Health Economics 16, 993-1008.

[25] Newhouse, J.P., 1977. Medical care expenditure: a cross-national survey. Journal of Human Resources 12, 115-125.

[26] Nixon, J., Ulmann, P., 2006. The relationship between health care expenditure and health outcomes. European Journal of Health Economics 7, 7-18.

[27] OECD, 2008. OECD Health Data 2008, CD-Rom and Users Guide. OECD: Paris.

[28] Or, Z., 2001. Exploring the effects of health care on mortality across OECD countries. OECD Labour Market and Social Policy Occasional Paper No. 46. OECD, Paris.

[29] Phillips, P.C.B. Sul, D., 2007a. Transition Modeling and Econometric Convergence Tests. Econometrica 75 (6), 1771-1855.

[30] Phillips, P.C.B. Sul, D., 2007b. Some Empirics on Economic Growth under Heterogeneous Technology. Journal of Macroeconomics 29, 455-469.

[31] Phillips, P.C.B., Sul, D., 2009. Economic Transition and Growth. Journal of Applied Econometrics 24 (7), 1153-1185..

[32] Wang, Z., 2009a. The determinants of health care expenditures: evidence from US state-level data. Applied Economics 41, 429-435.

[33] Wang, Z., 2009b. The convergence of health care expenditure in the US states. Health Economics 18, 55-70. 
Figure 1. Relative transition paths for per capita health expenditure

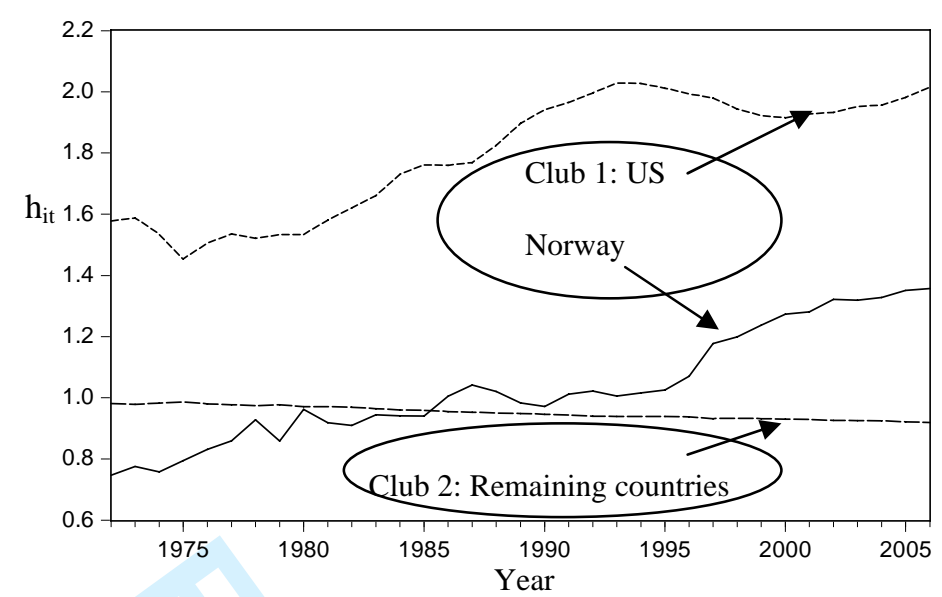

Note: Each oval represents a convergent club. Each line (i.e. transition path) shows the position of the country or club relative to the panel average. The 19-country average corresponds to the unity level. A transition path below unity indicates that the level of the country or club is below the panel average, while a transition path above unity indicates that the level of the country or club is above the panel average.

Figure 2. Relative transition paths for 'health care expenditure as a share of GDP' (lefthand side) and 'labour productivity' (right-hand side)
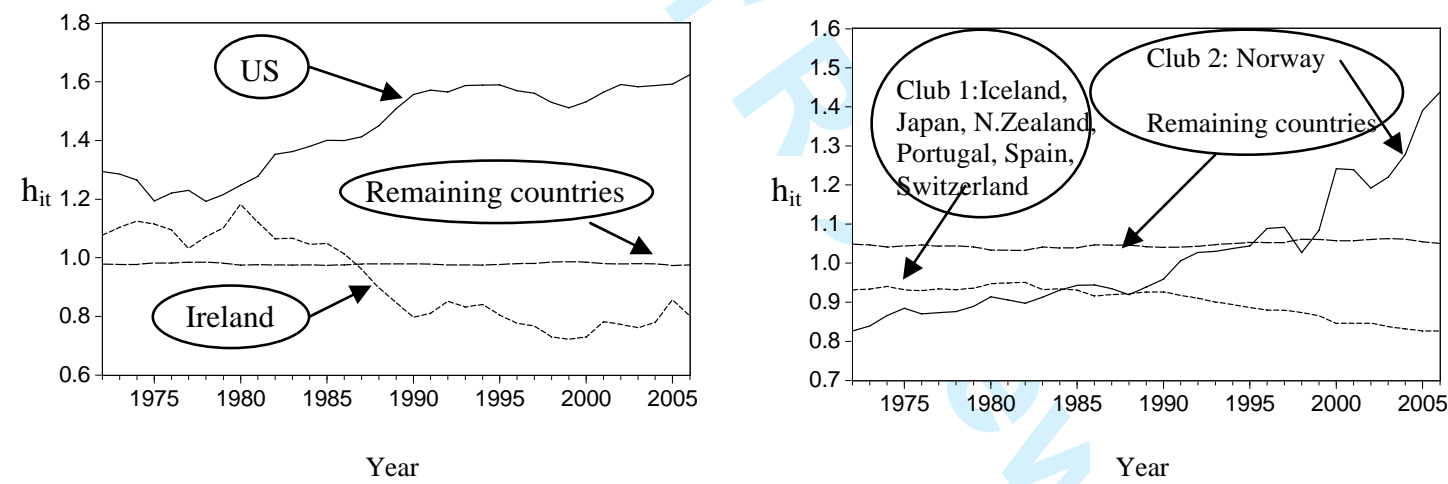

Note See Figure 1. 
Figure 3. Club convergence - Health outcomes
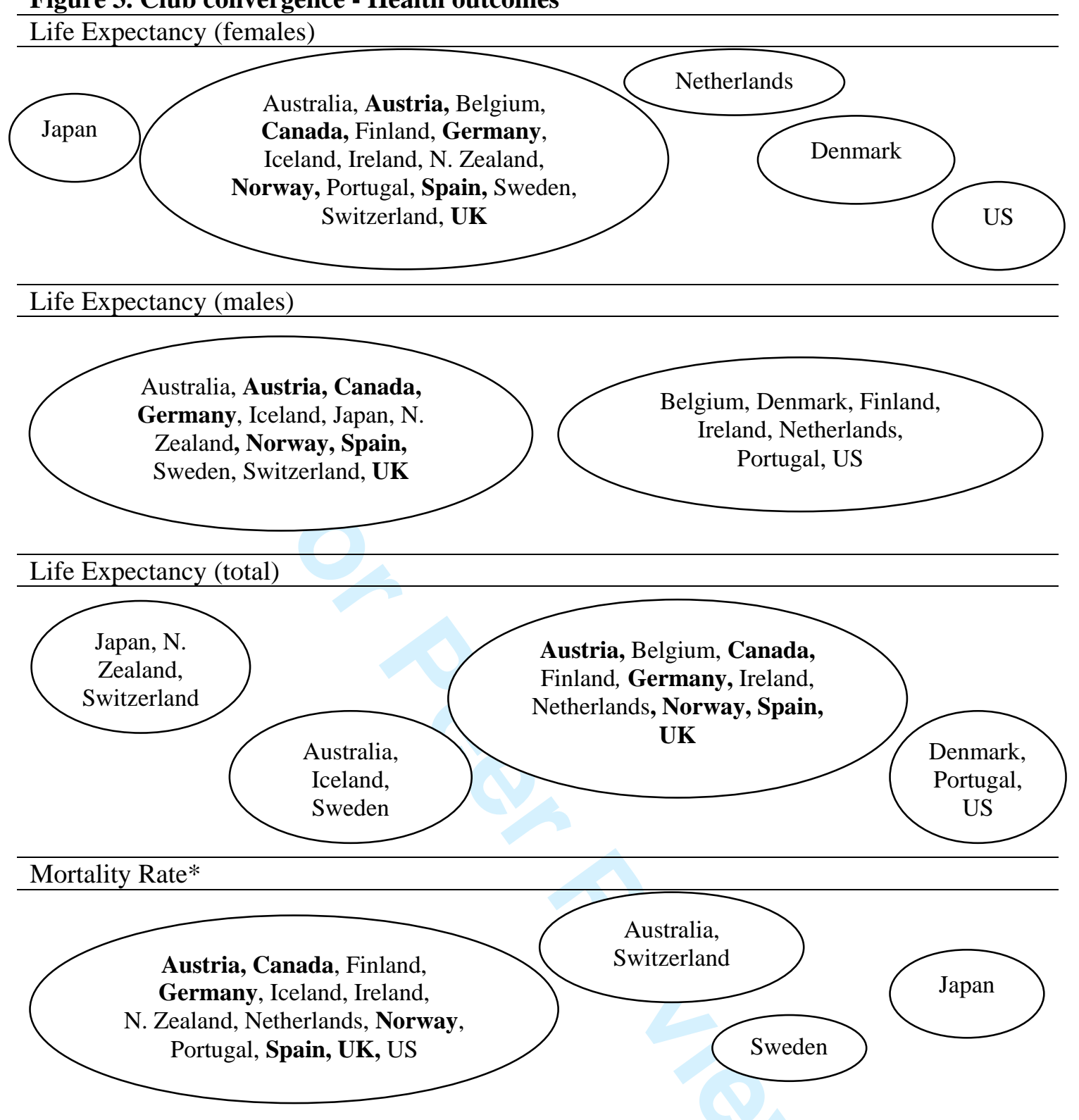

Potential Years of life lost $(<70))^{*}$
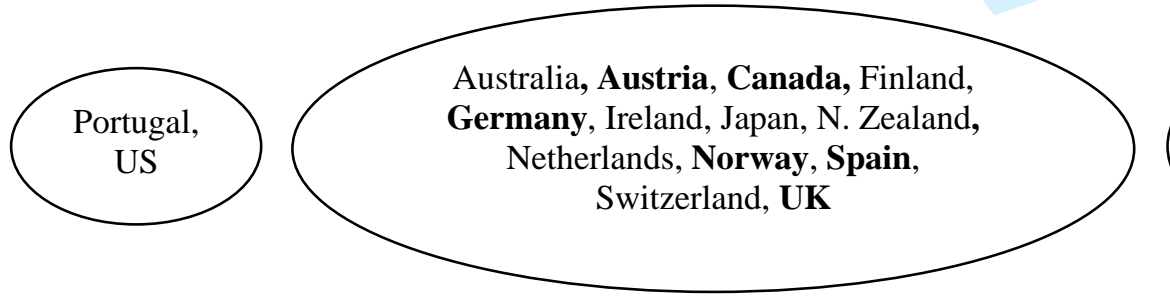

Iceland, Sweden

Notes: $(*)$ Belgium and Denmark are excluded from the analysis due to data unavailability.

Each oval represents a convergent club. The order of the clubs shows the ordering of the relevant transition curves. Moving to right suggests moving from high-level to low-level club. Bold indicates membership to the core group of countries that belong to the same club for all the variables at hand. 
Table 1. List of countries and variables

\begin{tabular}{llll}
\hline \multicolumn{2}{l}{ Panel A: List of countries } & & \\
\hline Australia & Austria & Belgium & Canada \\
Denmark & Finland & Germany & Iceland \\
Ireland & Japan & Netherlands & New Zealand \\
Norway & Portugal & Spain & Sweden \\
Switzerland & UK & US & \\
\hline
\end{tabular}

Panel B: List of variables / definitions

\begin{tabular}{|c|c|c|}
\hline Variable & Definition - Expressed in & Availability \\
\hline Per capita health expenditure & Total expenditure on health /capita - US\$ PPP & 1972-2006 \\
\hline $\begin{array}{l}\text { Health care expenditure as a share of } \\
\text { GDP }\end{array}$ & $\begin{array}{l}\text { Total expenditure on health - \% gross domestic } \\
\text { product }\end{array}$ & 1972-2006 \\
\hline Labour productivity & $\begin{array}{l}\text { Gross domestic product - Million US\$, PPP } \\
\text { /Total employment - Thousands of persons } * 100\end{array}$ & 1972-2006 \\
\hline Employment rate & $\begin{array}{l}\text { Total employment - Thousands of persons/ } \\
\text { Labour force - Thousands of persons }\end{array}$ & 1972-2006 \\
\hline Activity rate & $\begin{array}{l}\text { Labour force - Thousands of persons/ } \\
\text { Population: } 15-64 \text { years - Thousands of persons }\end{array}$ & 1972-2006 \\
\hline $\begin{array}{l}\text { Ratio of working-age population to } \\
\text { total population }\end{array}$ & $\begin{array}{l}\text { Population: } 15-64 \text { years - Thousands of persons/ } \\
\text { Total population - Thousands of persons }\end{array}$ & 1972-2006 \\
\hline & Fom Jloc at hirth - Yourc & \\
\hline $\begin{array}{l}\text { Lite expectancy (Iemales) } \\
\text { Life expectancy (males) }\end{array}$ & $\begin{array}{l}\text { Memales at Dirth - Years } \\
\text { Males at birth - Years }\end{array}$ & $\begin{array}{l}1980-2005 \\
1980-2005\end{array}$ \\
\hline Life expectancy (total) & Total population at birth - Years & 1980-2005 \\
\hline Mortality rate & All causes - Deaths /100000 population & $\begin{array}{l}\text { 1972-2003 excl. } \\
\text { Belgium \& Denmark }\end{array}$ \\
\hline Infant mortality & Infant mortality - Deaths /1 000 live births & 1972-2005 \\
\hline Potential years of life lost $(<70)$ & All causes - <70 year /100 000 population & $\begin{array}{l}\text { 1972-2003 excl. } \\
\text { Belgium \& Denmark }\end{array}$ \\
\hline GDP per capita & Gross domestic product /capita - US\$ PPP & 1972-2006 \\
\hline Inflation & $\begin{array}{l}\% \text { change in GDP deflator (Gross domestic } \\
\text { product - Price index }(2000=100))\end{array}$ & $1973-2003$ \\
\hline Income equality & $\begin{array}{l}\text { Compensation of employees - \% gross domestic } \\
\text { product }\end{array}$ & $\begin{array}{l}\text { 1972-2005 excl. } \\
\text { Germany }\end{array}$ \\
\hline Baumol variable & $\begin{array}{l}\text { Growth in Compensation of employees - } \\
\text { Growth in labour productivity }\end{array}$ & $\begin{array}{l}\text { 1973-2005 } \\
\text { excl. Germany }\end{array}$ \\
\hline Public health expenditure & Public expend. on health - \% total exp. on health & $\begin{array}{l}\text { 1972-2006 } \\
\text { Excl. Belgium }\end{array}$ \\
\hline Dependency ratio & $\begin{array}{l}\text { Age dependency ratio - Population 0-14 \& } \\
65+/ \text { pop.15-64 }\end{array}$ & 1972-2006 \\
\hline $\begin{array}{l}\text { Ratio of under-14 population to total } \\
\text { population }\end{array}$ & Population: 0-14 years - \% total population & 1972-2006 \\
\hline $\begin{array}{l}\text { Ratio of over-65 population to total } \\
\text { population }\end{array}$ & Population: 65 and over - \% total population & 1972-2006 \\
\hline Female labour force participation rate & Labour force - \% females in labour force & $\begin{array}{l}\text { 1975-2002 excl. } \\
\text { Belgium \& Iceland }\end{array}$ \\
\hline Sugar consumption & Sugar consumption - Kilos per capita & 1972-2003 \\
\hline Fruits \& vegetables consumption & Fruits and vegetables - Kilos per capita & 1972-2003 \\
\hline Tobacco consumption & Tobacco consumption - Grammes /capita (15+) & $\begin{array}{l}\text { 1980-2001 excl. } \\
\text { Austria, Belgium, } \\
\text { Ireland, Japan, } \\
\text { Portugal \& Spain }\end{array}$ \\
\hline Alcohol consumption & Alcohol consumption - Liters /capita (15+) & $\begin{array}{l}\text { 1972-2003 excl. } \\
\text { Germany }\end{array}$ \\
\hline
\end{tabular}


Table 2. Per capita health-care expenditure decomposition - Convergence tests

\begin{tabular}{|c|c|c|}
\hline & $\hat{b}$ & $t_{b}$-stat \\
\hline Per capita health expenditure & $-0.471 *$ & -5.024 \\
\hline \multicolumn{3}{|l|}{ Factor Decomposition } \\
\hline & $\hat{b}$ & $t_{b}-$ stat \\
\hline Health care expenditure as a share of GDP & $-0.850 *$ & -16.498 \\
\hline Labour productivity & $-0.562 *$ & -7.624 \\
\hline Employment rate & 0.838 & 2.535 \\
\hline Activity rate & 0.118 & 0.679 \\
\hline Ratio of working-age population to total population & 0.887 & 4.806 \\
\hline
\end{tabular}

Notes: * indicates rejection of the null hypothesis of convergence at the $5 \%$ level.

Table 3. Health outcomes, economic variables, demographic variables, life-style and behavior - Convergence Tests

\begin{tabular}{|c|c|c|}
\hline \multicolumn{3}{|l|}{ Panel A: Health outcomes } \\
\hline 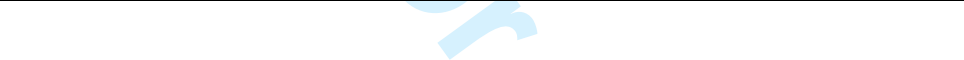 & $\hat{b}$ & $\mathrm{t}_{\mathrm{b}}$-stat \\
\hline Life expectancy (females) & $-0.772 *$ & -17.752 \\
\hline Life expectancy (males) & $-0.476^{*}$ & -6.613 \\
\hline Life expectancy (total) & $-0.554 *$ & -8.555 \\
\hline Mortality rate & $-0.619 *$ & -12.776 \\
\hline Infant mortality & -0.201 & -0.743 \\
\hline Potential years of life lost $(<70)$ & $-0.597 *$ & -8.869 \\
\hline \multicolumn{3}{|l|}{ Panel B: Economic variables } \\
\hline & $\hat{b}$ & $\mathrm{t}_{\mathrm{b}}$-stat \\
\hline GDP per capita & -0.034 & -0.489 \\
\hline Income equality & $-1.524^{*}$ & -13.213 \\
\hline Inflation & -0.008 & -0.030 \\
\hline Baumol variable & -1.678 & -1.174 \\
\hline Public health expenditure & -0.037 & -0.369 \\
\hline \multicolumn{3}{|l|}{ Panel C: Demographic variables } \\
\hline & $\hat{b}$ & $\mathrm{t}_{\mathrm{b}}$-stat \\
\hline Dependency ratio & 0.915 & 4.451 \\
\hline Ratio of under-14 population to total population & $-0.377 *$ & -6.538 \\
\hline Ratio of over-65 population to total population & $-0.337^{*}$ & -6.091 \\
\hline Participation in labour force of females & 1.156 & 17.270 \\
\hline \multicolumn{3}{|l|}{ Panel D: Life-style and behavior } \\
\hline & $\hat{b}$ & $t_{b}-$ stat \\
\hline Sugar consumption & $-1.004^{*}$ & -17.770 \\
\hline Fruits \& vegetables & $-0.368 *$ & -2.107 \\
\hline Tobacco consumption & $-1.573^{*}$ & -18.823 \\
\hline Alcohol consumption & -0.042 & -0.580 \\
\hline
\end{tabular}

Notes: * indicates rejection of the null hypothesis of convergence at the $5 \%$ level. 